\title{
CONTRIBUIÇÕES ACERCA DO USO DO SINTOMA NA CLÍNICA DE ORIENTAÇÃO WINNICOTTIANA
}

Resumo expandido, temática: Psicologia Clínica.

Jaqueline Cristina Salles Trindade - Psicóloga pela PUC-Minas e Doutoranda em Memória, Linguagem e Sociedade pela UESB. Maria da Conceição Fonseca-Silva Pós-Doutorado em Linguística pela Unicamp e docente pesquisadora da UESB. Auterives Maciel Junior - Doutor em teoria Psicanalítica pela UFRJ e docente da Universidade Veiga de Almeida (UVA). jaquelinesalles@gmail.com

\section{RESUMO}

A teoria do desenvolvimento emocional criada por Winnicott rediscute e propõe uma nova designação para a psicopatologia, sempre em referencia à saúde, ou seja, partindo das condições facilitadoras, que colocam a vida em movimento, e o uso ou função do sintoma e do adoecimento como tentativas de retomada da saúde emocional. Partindo desta compreensão este estudo tem como objetivo apresentar as contribuições de Winnicott acerca do uso do sintoma como indicativo de saúde emocional. Por meio de uma pesquisa qualitativa de cunho bibliográfico, selecionamos as principais obras em que o autor aborda este tema e sua compreensão clínica. Nossos resultados assinalam que é a partir do que acontece "normalmente" no amadurecimento de uma criança que permite avaliar e compreender as doenças ou imaturidades persistentes. Esta designação é nova na psicanálise, visto que o sintoma sempre foi visto como um mecanismo de defesa contra a não satisfação instintual, como destino para a pulsão. Observa-se que nos quadros denominados de neurose, o individuo tem maiores condições de acionar recursos subjetivos para lidar com as adversidades do amadurecimento, de modo que os sintomas podem ser usados como indicativos de saúde emocional e não apenas como patologia. Tal compreensão aponta para a necessidade de uma escuta atenta e da importância de questionar-se se o paciente consegue fazer uso do sintoma no trabalho clínico. E especialmente, quando o sintoma deixa de existir, ou seja, perde a esperança em ser comunicado.

Palavras-chave: sintoma; clínica psicanalítica; Winnicott; saúde emocional; 


\section{INTRODUÇÃO}

Foi a partir do trabalho como pediatra no hospital que Donald D. Winnicott teve contado com adoecimentos em bebês antes mesmo de estes poderem falar. Um dos textos iniciais de 1931 ele já observava que crianças pequenas poderiam viver dificuldades emocionais as quais poderiam ser constatadas pela cuidadosa observação da relação entre dificuldades no crescimento ou doenças físicas como sinalizadoras de sofrimento emocional. Desde este texto, Winnicott introduz a formação dos sintomas ansiosos como relativos às dificuldades ambientais, ou seja, não relativas ao psíquico propriamente dito, mas, sobretudo ao modo como a criança é capaz de comunicar ${ }^{1}$ o que ela vive ou sente. No decorrer de seu trabalho como psicanalista, tratando de crianças, adolescentes e pacientes psicóticos, Winnicott ampliou a compreensão acerca da psicopatologia e reconfigurou a importância do sintoma a partir da observação e cuidado de crianças e os desdobramentos teóricos acerca das condições para que a saúde emocional aconteça.

Um dos questionamentos que o levaram a rever o sentido do sintoma deu-se na constatação de que a vida em si é difícil e que mesmo um bebê precisa lidar com necessidades as quais não está preparado e por isso a distinção entre normalidade e anormalidade é discutida e revisada por Winnicott dados os diferentes contextos ambientais e condições pessoais da vida. A partir deste entendimento, a saúde emocional será vista como a capacidade que um bebê e a criança têm de fazer uso dos diversos recursos subjetivos, como defesa contra angústias e conflitos. Deste modo, não é o sintoma em si o que é patológico, pois ele é necessário para lidar com a vida, mas o uso do mesmo que pode se tornar patológico. "A anormalidade revela-se numa limitação e numa rigidez na capacidade infantil para empregar sintomas, e uma relativa carência de relações entre os sintomas e aquilo e o que se pode esperar como auxilio". (WINNICOTT, 1957, p.149). Como exemplo, ele dirá sobre a criança que urina na cama, comportamento comum na infância, o qual nem sempre se refere a um sintoma patológico, podendo inclusive representar a reinvindicação de um direito pessoal contra

\footnotetext{
${ }^{1}$ Embora não trate como este termo neste momento, a comunicação é um conceito muito importante para a clínica psicanalítica de Winnicott.
} 


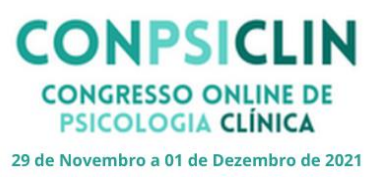

uma imposição severa, e por isso um sinal de saúde. O sintoma poderá ser abandonado assim que outros métodos possam ser utilizados como afirmação da personalidade. Desta forma, os sintomas são naturais, compõem o processo do crescimento e um recurso importante para enfrentar as adversidades inerentes à vida.

Importa sobremaneira pensarmos o que comunica esse sintoma, mais do que o conteúdo a ele subjacente, visto que os sintomas são como mensagens ao ambiente do que a criança sente por estar viva. Os sintomas podem tornar-se padrão de adoecimento quando deixam de comunicar ao ambiente suas necessidades, precisando assim ficar contidos e distorcidos daquilo que a criança sente, impedindo o curso do seu desenvolvimento. Dada a importância da escuta do sintoma na clínica de orientação psicanalítica, este trabalho objetiva apresentar as contribuições de Winnicott acerca do uso do sintoma como indicativo de saúde emocional.

\section{METODOLOGIA}

Dada à especificidade das contribuições teóricas de Winnicott acerca da psicopatologia e do sintoma, esta pesquisa se orientou pela adoção do método de pesquisa qualitativa. Quanto ao procedimento, à realização de uma pesquisa bibliográfica sobre esta questão nas principais obras do autor que abordam a temática da saúde emocional, psicopatologia e sintoma. A fim de cumprirmos nosso objetivo, selecionamos textos da obra "Pediatria à Psicanálise", de 1949, "O ambiente e os processos de maturação", de 1963; e uma de suas obras finais "Natureza Humana" de 1988.

\section{RESULTADOS E DISCUSSÕES}

Para Winnicott, saúde refere-se ao seguir sendo da vida, em que relação com a realidade é uma conquista e um avanço na sociabilidade e nas condições para viver a vida fora do âmbito familiar e restrito das patologias psicóticas, por exemplo. Defende que se compreenda a saúde de modo dinâmico com "padrões de conciliação entre êxito e fracasso no estado de desenvolvimento emocional do indivíduo. Deste modo, saúde é maturidade emocional, maturidade de acordo com a idade; e doença mental tem, subjacente, uma detenção da mesma" (WINNICOTT, 1963, p. 200). Embora o ambiente tenha função primordial na conquista da saúde, é importante destacar que para este autor, não é o ambiente que produz saúde, mas a tendência inata da natureza humana no 


\section{CONPSICLIN \\ CONGRESSO ONLINE DE \\ PSICOLOGIA CLÍNICA \\ 29 de Novembro a 01 de Dezembro de 2021}

sentido do crescimento e da integração alcançada pela diferenciação eu-outro. No entanto, "ainda assim é necessária provisão suficientemente boa, de forma absoluta no princípio e de forma relativa em estágios posteriores, no estágio do complexo de Édipo, no período de latência e também na adolescência". As distorções no processo de desenvolvimento que colocam a dependência como impossibilitada ou demasiadamente necessária serão indicativos significativos para a compreensão do adoecimento. (WINNICOTT, 1962, p.65).

Segundo Winnicott (1988), a compreensão da saúde emocional da criança e posteriormente do adulto foi pensada por Freud a partir da vida instintual especificamente com base na sexualidade infantil e da vivência edípica. O individuo que sofre de conflitos oriundos das relações interpessoais, são chamados, na semântica winnicottiana, de pessoas inteiras, que sofrem de adoecimentos do tipo neurótico. Os sintomas neuróticos são compreendidos como manifestação de saúde emocional, por referirem-se a conquistas no amadurecimento que permitem a formação do ego de modo fortalecido e que é capaz de lidar com a realidade e com toda gama de emoções e sentimentos advindos da relação com o mundo.

Neste aspecto, Winnicott rediscute o termo saúde emocional, por constatar que anterior à vivência do Complexo de Édipo há a necessidade da oferta de importantes condições ambientais para a constituição do Eu ou de uma pessoa inteira. A conquista do desenvolvimento emocional é vista como uma possibilidade para cada indivíduo, podendo ou não se realizar, pois a tendência à integração depende das condições ofertadas para que o continuar a ser do bebê siga no amadurecimento. É assim que para Winnicott, o sintoma nem sempre se refere ao quadro patológico e em termos de recursos subjetivos pode-se observar que "as defesas organizadas na neurose apontam o caminho para a ansiedade, que não apenas se encontra por trás do sintoma neurótico, mas também fornece a força e a qualidade das manifestações da saúde” (1988, p.55).

O caminho criado por Winnicott foi pensar as bases do desenvolvimento emocional primitivo que poderiam fornecer respostas para a psicose e o sofrimento decorrente antes da vivencia de relacionamentos entre pessoas, de como os sintomas terão usos distintos entre pessoas que sofrem de um quadro de neurose daqueles que sofrem de um quadro psicótico. Neste trabalho nos deteremos ao uso do sintoma nos 


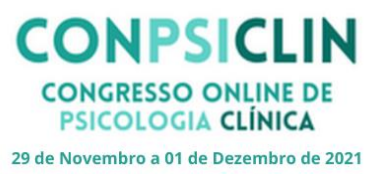

quadros da neurose, os quais tendem a acontecer quando o bebê vive em um ambiente facilitador ao seu amadurecimento. As tarefas ambientais acontecem de forma concomitante e referem-se, sobretudo à fase de dependência absoluta, durante os primeiríssimos meses de vida, as quais lançam as bases para a saúde. Cada um dos estágios do amadurecimento terão conquistas emocionais específicas que poderão oportunizar o aumento de recursos subjetivos do bebê para lidar tanto com realidade externa quanto com o que acontece "dentro" dele. Do ponto de vista didático, aquele que cresce sem muitos percalços, ou seja, sem rupturas que paralisam o amadurecimento, vive as fases de dependência sem traumas significativos, tendo por isso, mais condições de fazer uso do recurso do sintoma como comunicação. Em linhas gerais, a fase de "dependência absoluta", em que o ambiente tem fundamental importância dado a precariedade do bebê, cria condições para que o bebê possa ir construindo um modo pessoal de lidar com a realidade, e o sintoma poderá ser um indicativo de interrupção na continuidade de ser, ou uma reação a intrusão ambiental, e por isso um indicativo de maior prejuízo emocional. Já na fase de "dependência relativa", o bebê que viveu a dependência tem uma gama maior de recursos subjetivos para lidar com o ambiente, de forma que os sintomas tendem a ser usados de modo a facilitar o bebê a lidar com as falhas ambientais. E já na fase chamada de "interdependência" ou de "rumo à independência", o bebê já conquistou a capacidade de se relacionar com o mundo, ainda que nada seja totalmente garantido em termos de vida emocional, e com isso o sintoma pode ser mais um recurso saudável de reivindicação ao ambiente do que propriamente patológico.

\section{CONSIDERAÇÕES FINAIS}

O percurso que realizamos neste trabalho nos aponta a importância da compreensão e escuta do sintoma não apenas como algo patológico na prática clínica. Por meio da teoria do amadurecimento, Winnicott faz uma importante contribuição ao reconfigurar a psicopatologia, ao demonstrar que doença é a perda de contato com a raiz da criatividade. Desta forma, o sintoma pode representar um recurso saudável desde que seja uma tentativa de comunicação com o ambiente, podendo assim ser usado como mais um recurso para lidar com $\mathrm{o}$ mundo $\mathrm{e}$ as adversidades inerentes ao amadurecimento. 


\section{CONPSICLIN}

CONGRESSO ONLINE DE

PSICOLOGIA CLÍNICA

29 de Novembro a 01 de Dezembro de 2021

\section{REFERÊNCIAS}

WINNICOTT, D. W. A criança e o seu mundo. Rio de Janeiro: LTC, 1982. Edição Original: 1957.

Winnicott, D. W. Da pediatria à psicanálise - Obras escolhidas. Rio de Janeiro: Imago, 2000. Edição original: 1949.

Winnicott, D. W. Natureza Humana. Rio de Janeiro: Imago, 1990. Edição original: 1988.

Winnicott, D. W. O ambiente e os processos de maturação: estudos sobre a teoria do desenvolvimento emocional. Porto Alegre: Artmed, 1983. Edição original: 1963.

WINNICOTT, D. W. Provisão para a criança na saúde e na crise. In: Winnicott, D. W. O ambiente e os processos de maturação. Porto Alegre: Artmed, 1983. Edição original: 1963. 